\title{
Study of skin degradation in ancient Egyptian mummies: complementarity of Fourier transform infrared spectroscopy and histological analysis
}

\author{
Mariachiara Stani, ${ }^{1}$ Andrea Baraldi, ${ }^{1}$ Rosa Boano, ${ }^{2}$ Rosangela Cinquetti, ${ }^{3}$ Maria Grazia Bridelli ${ }^{1}$ \\ ${ }^{1}$ Department of Physics and Earth Sciences, University of Parma; ${ }^{2}$ Department of Animal and \\ Human Biology, University of Torino; ${ }^{3}$ Department of Bioscience, University of Parma, Italy
}

\begin{abstract}
Some dynastic and pre-dynastic Egyptian mummies from the Giovanni Marro Museum of Anthropology and Ethnography, University of Turin, Italy have been studied by means of the combined approach of both Fourier transform infrared spectroscopy and histological analysis, with the aim of investigating the preservation state of the skin of ancient archaeological remains, as a consequence of the differences between the two kinds of mummification processes, i.e. natural and by means of embalming substances. The results suggest that the balms used in the dynastic mummies embalming process really could have played an important role in the prevention of corpse deterioration.
\end{abstract}

\section{Introduction}

Several layers can be distinguished in the structure of the human skin, where it is possible to recognize epidermis, derma and hypoderm. Epidermis is composed of different layers characterized by a different amount of keratin from the inner to the surface layer. Derma is mostly composed of collagen fibers, interspersed among a network of elastic fibers, immersed in the extracellular matrix of glycosaminoglycans. Hypoderm is mostly composed of adipose cells, the adipocytes. Mummification, both the natural and embalming process, even though it induces modification in the skin structure and morphology. Moreover, it preserves tissues from decay, providing a conservative aging of the bodies, able to resist degradation over thousands of years. In the present work measurements were carried out by means of the

Correspondence: Mariachiara Stani, Department of Physics and Earth Sciences, University of Parma, via G.P. Usberti 7/a, 43124 Parma, Italy.

Tel. +39.0521 .905222 - Fax: +39.0521 .905322 .

E-mail: chiaramaria.stani@difest.unipr.it

Key words: dynastic and pre-dynastic mummy, skin, secondary structure of proteins, FTIR spectroscopy, histology.

(c) Copyright M. Stani et al., 2014

Licensee PAGEPress, Italy

Journal of Biological Research 2014; 87:2133

doi:10.4081/jbr.2014.2133

This article is distributed under the terms of the Creative Commons Attribution Noncommercial License (by-nc 3.0) which permits any noncommercial use, distribution, and reproduction in any medium, provided the original author(s) and source are credited. combined use of Fourier transform infrared (FTIR) spectroscopy and histological analysis in order to study the skin structure and texture of three Egyptian mummies, one belonging to the pre-dynastic age, recently dated from about $3600 \mathrm{BC},{ }^{1}$ and two of the dynastic period (VIXI dynasties) conserved in the Giovanni Marro Museum of Anthropology and Ethnography, University of Turin, Italy.

FTIR spectroscopy is a powerful technique to study skin proteins. In the infrared (IR) spectrum, the protein repeat unit, the peptidic backbone, originates nine characteristic IR absorption bands, Amide bands (A, B and I-VII). ${ }^{2}$ Amide I band ( $\approx 1650 \mathrm{~cm}^{-1}$ ) due to $\mathrm{C}=0$ stretch vibration (80\%) and C-N stretch vibration (20\%) is particularly sensitive to the secondary structure of the protein: the deconvolution of the band into its Gaussian components can be correlated to the conformational composition. ${ }^{3}$ The degradation status of the ancient remains was evaluated from the molecular alterations of the skin proteins like keratin, collagen, and elastin. To better support these findings, histological analyses able to describe the tissue structural features and morphology have also been carried out. The results have been discussed and compared.

\section{Materials and Methods}

\section{Sample}

Small skin fragments were taken from three Egyptian mummies. The first specimen, named PRED (Figure 1a), was taken from a predynastic mummy, a body naturally mummified. It is yellow-colored and not embalmed. The second and the third samples, named 9092 (Figure $1 \mathrm{~b} 1$ and 1b2) and 996 (Figure 1c), respectively, belonging to two dynastic mummies, therefore artificially mummified, were taken, the former from the mandibular corner, and the last one from the scalp where some hair can be distinguished, visible to the naked eye.

The samples from dynastic mummies are brown-colored because they are covered by embalming substances. A modern skin sample, taken from the hand of one of the authors, was used as a reference. All samples were observed and photographed by an optical microscope.

\section{Fourier and $\mu$ Fourier transform infrared spectroscopy}

All samples were studied by means of FTIR and $\mu$ FTIR spectroscopy as described in previous works. ${ }^{4,5}$ Measurements in transmission mode were performed by means of a Jasco 420 spectrophotometer (Jasco Products Company, Oklahoma City, OK, USA; 4000-400 cm-1, 128 scans, spectral resolution $2 \mathrm{~cm}^{-1}$ ) on samples prepared as potassium bromide (KBr) pellets ( 1 mg of sample ground in $100 \mathrm{mg}$ of $\mathrm{KBr}) . \mu \mathrm{FTIR}$ measurements were performed by means of a BOMEM DA8 spectrophotometer (1000 scans, spectral resolution $1 \mathrm{~cm}^{-1}$ ) coupled to an IR PLAN microscope, focusing the beam light in small areas $\left(0.4 \times 0.4 \mathrm{~mm}^{2}\right)$ of samples. 


\section{Histological analyses}

Skin samples underwent several treatments to prepare tissues for the inspection. Samples were prepared with and without fixative solution to better understand the role of the fixative procedure on ancient or mummified tissues. They were rehydrated in distilled water and then immersed in paraformaldehyde (2\%)/glutaraldehyde (2.5\%) fixative solution at $4^{\circ} \mathrm{C}$ for $12 \mathrm{~h}$. Then they were dehydrated with grading series of ethanol and diafanised with toluene. Afterwards they were immersed for several hours 2 times in paraffin to procure the total toluene elimination and paraffin infiltration and finally embedded in paraffin until a complete wax hardening occurred. Sections of $6 \mu \mathrm{m}$ thick were cut by a microtome, as described in literature. ${ }^{6,7}$ Tissue sections were mounted on the slides and deparaffinized by xylene, rehydrated in a grading series of ethanol, washed with distilled and tap water and stained by Mayer's hemalum and eosin (some sections) and by Verhoeff-Van Gieson solution (other sections). The last staining technique is specific for the elastic fibers. Coverslips with resinous mounting medium were used to seal up specimens on the slides.

\section{Results and Discussion}

It is well known that skin collagen is a fibrous protein composed by three polyproline helices tightly rolled up in a triple helix. ${ }^{8}$ The deconvolution analysis on FTIR Amide I bands for the mummified samples spectra shows a different conformational composition, if compared to modern skin sample, as discussed in previous papers., ${ }^{4,5}$ The results obtained and the deconvolution data are here summarized in Figure 2.

As displayed in Figure 2, the percentage amount of -helix in PRED sample is very low (13\%) as compared to the content detected in 9092 and 996 ones (respectively 52 and 38.1\%) and in modern skin (73\%). The low -helix content, accompanied by a considerable increase in the -sheet motif, might be interpreted as a partial unfolding effect of the native collagen structure in the mummified remains where dehydration and aging could have produced protein conformational alterations, as shrinkage and/or lengthening of the triple helix.

Histological analyses confirm spectroscopical measurements.
Dynastic and pre-dynastic samples exhibit remarkable differences in the general architecture of the skin. In all the samples neither epidermis nor other types of cells can be observed and, although derma collagen fibers are well recognizable in every samples, they display different appearance in the different specimens.

PRED sample collagen fibers are bluish-purple stained and show a liquid-like appearance (Figure 3b). In the fixed dynastic sample 9092 (Figure $3 c$ ) they are deeply pink stained and show features resembling those in modern skin (Figure 3a). Verhoeff-Van Gieson staining points out the presence of black filamentous structures insinuating among the pink collagen fibers (Figure $3 \mathrm{cl})^{7}$ which can be hypothesized to be elastic fibers.

In the 996 dynastic sample two layers of collagen bundles are clearly
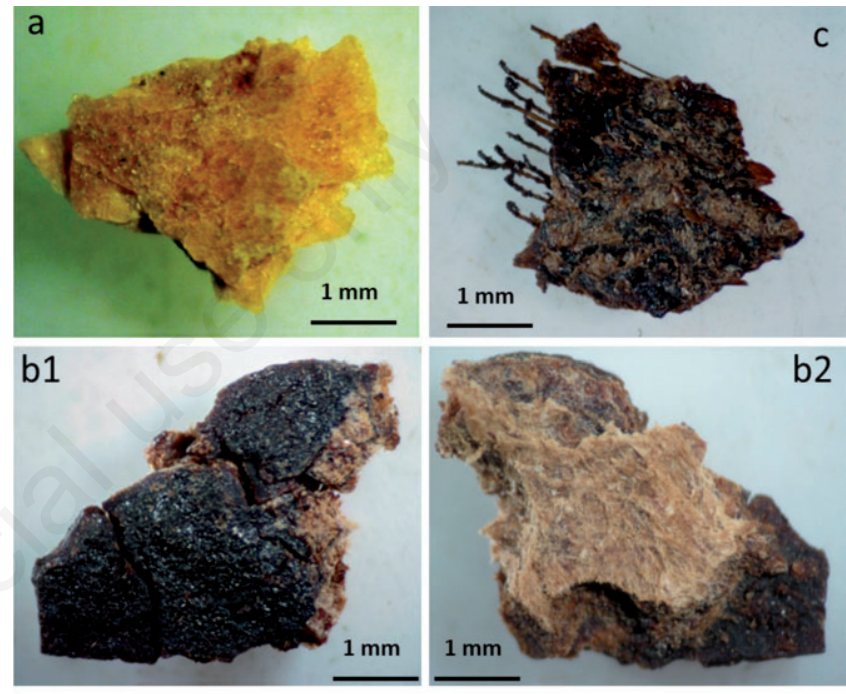

Figure 1. a) Pre-dynastic mummy skin; b) sample 9092-dynastic mummy skin (b1=outer layer, b2=inner layer); c) sample 996skin from the scalp of a dynastic mummy.

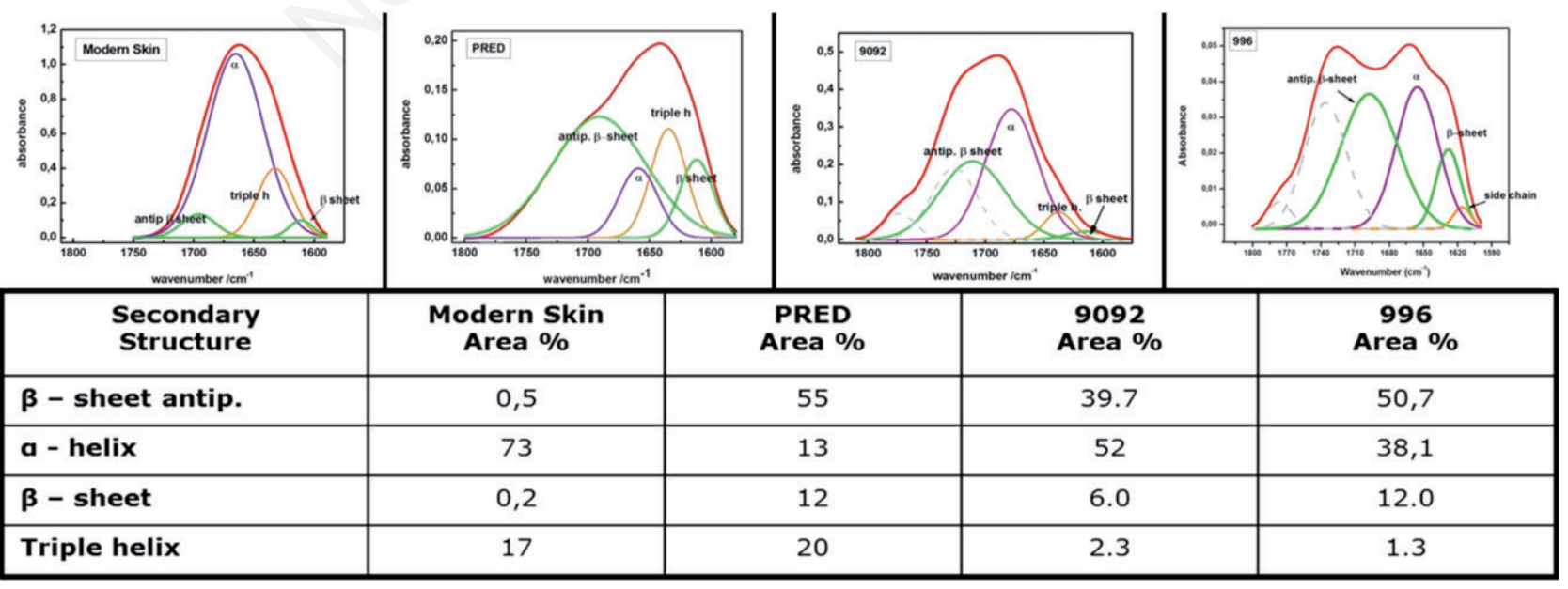

Figure 2. Amide I bands analysis. Up: Fourier transform infrared spectroscopy Amide I band analyzed by the deconvolution method. Down: table listing the percentage amounts of each secondary structure calculated from the corresponding Gaussian band area as related to the total band area measured for each sample. $P R E D=$ pre-dynastic. 
discernible, separated by an empty space (for a comparison see Figure $4 a)^{9}$. The first one displays a brownish-yellow coloration (Figure $4 \mathrm{~b}$ and 4c) which may be attributed to the embalming substances soaking into the collagen fibers. FTIR results support the interpretation: Amide I band, measured on the same sample, is affected by a huge extra-protein band ( $\mathrm{n} 1720 \mathrm{~cm}^{-1}$ ), corresponding to the lipid $\mathrm{C}=0$ stretching vibrations, probably due to the balm penetrated through the skin surface. Among these structures, some hair follicles are clearly visible. The hair appears well preserved and medulla, cortex and cuticle can be recognized (Figure 4d). In the second layer, collagen fibers are deeply pink stained and show a thinner structure (Figure 4b) than the fibrils in the first layer. It could represent galea capitis layer ${ }^{10}$ and the optically empty space might be the space originally occupied by hypoderm, which is degraded.

\section{Conclusions}

In conclusion, the present study emphasizes the powerful role of the combined application of the two techniques, histology and FTIR spectroscopy, to the study of ancient mummified skins. The main results attained may be summarized as follows.

Both the techniques agree in the representation of collagen bundles modified by aging, thinned and stretched as compared with the native macromolecules, as a result of the dehydration and as a consequence of the mummification process.

Pre-dynastic mummy skin appears in a worse state of preservation if compared to the skin of the two dynastic mummies. This fact suggests that the embalming process is indeed more successful in preserving tissues from deterioration than natural mummification.

The observation of histological sections revealed that in the predynastic mummies only collagen fibrous structures of extracellular matrix seem to be preserved. As concerns the identification of elastic fibers, additional specific histochemical techniques with elastase should be implemented in the future.

\section{References}

1. Zink A, Samadelli M. [Datazione al radiocarbonio della mummia predinastica presso il Museo di Antropologia di Torino]. In: Boano $\mathrm{R}$ and Rabino Massa E, eds. [Proc. Mummie egizie in Piemonte. Storia ed attualità in ambito egittologico ed antropologico, Nov. 2012]. [Proc. in Italian]. 2012.

2. Kong J, Yu S. Fourier transform infrared spectroscopy analysis of protein secondary structure. Acta Bioch Bioph Sin 2007;39:549-59.

3. Torii H, Tasumi M. Theoretical analyses of the Amide I infrared bands of globular proteins. In: Mantsch HH and Chapman D, eds. Infrared spectroscopy of biomolecules. New York, NY: John Wiley \& Sons;1996. pp 1-18.

4. Bridelli MG, Dell'Anna A, Stani C, et al. FT-IR spectroscopy and microspectroscopy of ancient Egyptian embalmed heads from the Museum of Anthropology and Ethnography of the University of Turin. Proceedings of the 2nd Bolzano Mummy CongressMummies from the ice, 2011 October -22, Bolzano, Italy.

5. Bridelli MG, Dell'Anna A, Stani C, et al. The preservation state of the skin of some embalmed heads from the Museum of Anthropology and Ethnography of the University of Turin: FTIR investigation of protein secondary structure. J Biol Res 2012;875:340-1.

6. Chang BS, Uhm CS, Park CH, et al. Preserved skin structure of a recently found fifteenth-century mummy in Daejeon, Korea. J Anat 2006;209:671-80.

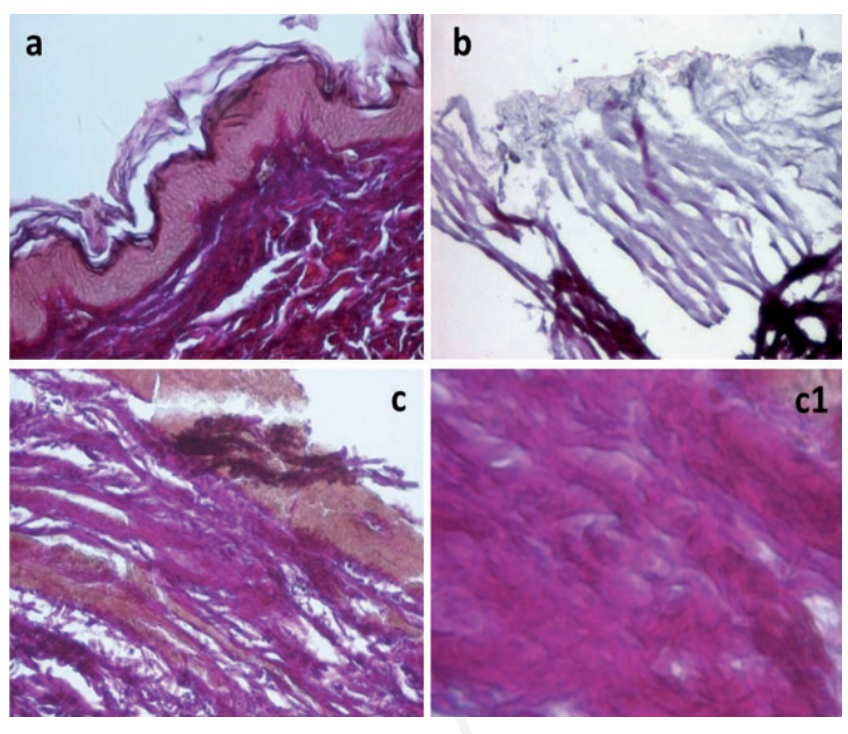

Figure 3. Histological sections. a) Modern skin (x120); b) PRED skin (x60); c) 9092 skin (x120); c1) magnification of c imagine (x480). Sample b) stained with Mayer's hemalum and eosin; samples a,c,c1) Verhoeff-Van Gieson stained. PRED=pre-dynastic.

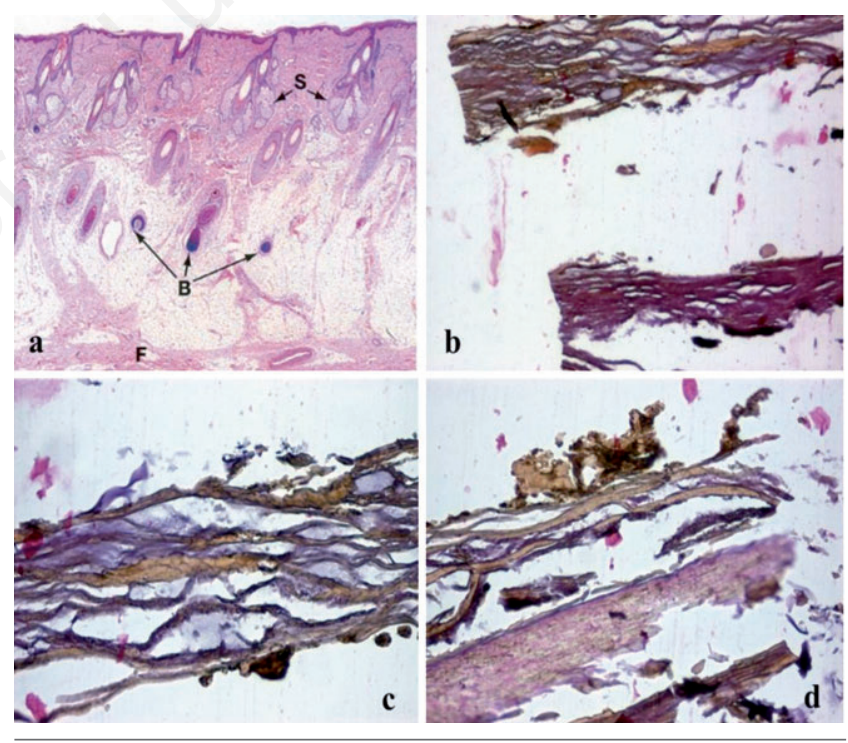

Figure 4. a) Modern skin [x12 (9)]; b) 996 sample (x30); c,d) magnified images of 996 sample (x60). All sections are Mayer's hemalum and eosine stained.

7. Montes GS, Krisztan RM, Junqueira LC. Preservation of elastic system fibers and of collagen molecular arrangement and stainability in an Egyptian mummy. Histochemistry 1985;83:117-9.

8. Rich A, Crick FH. The molecular structure of collagen. J Mol Biol 1961;3:483-506.

9. Young B, Luwe JS, Stevens A, Health JW. [Wheater. Istologia e anatomia microscopica]. [Book in Italian]. Amsterdam: Elsevier; 2007.

10. Ottaviani G. [Manuale di anatomia topografica]. [Book in Italian]. Parma: Santa Croce Publ.; 2008. 